\title{
EFEITO DO TIPO DE CULTIVAR, DESPENDOAMENTO DAS PLANTAS E DA ÉPOCA DE SEMEADURA NA PRODUÇÃO DE MINIMILHO
}

\author{
GRACIELA SILVA CARVALHO ${ }^{1}$; RENZO GARCIA VON PINHO²; ISRAEL ALEXANDRE \\ PEREIRA FILHO ${ }^{3}$
}

\begin{abstract}
${ }^{1}$ Eng. Agrônomo, MSc., Universidade Federal de Lavras. Caixa Postal 37, CEP. 37200-000 Lavras, MG.
${ }^{2}$ Eng. Agrônomo, DSc., Professor, Departamento de Agricultura, Universidade Federal de Lavras. Caixa Postal 37, CEP.37200-000 Lavras, MG. E-mail: renzo@ufla.br (autor para correspondência)

${ }^{3}$ Pesquisador, Embrapa Milho e Sorgo. Caixa Postal 151, CEP. 35700-000 Sete Lagoas, MG.
\end{abstract}

Revista Brasileira de Milho e Sorgo, v.1, n.3, p.47-58, 2002

\begin{abstract}
RESUMO - Minimilho, também conhecido como "baby corn", é o nome dado à espiga jovem, em desenvolvimento, não fertilizada de uma planta de milho. Com o advento da indústria de conservas, o minimilho passou a ser consumido também na forma de conservas. Assim, houve um crescimento na área cultivada com milho para consumo nessa forma, à semelhança do acontecido com o milho verde. Diferentes tipos de cultivares de milho, como doce, pipoca e mesmo milho normal têm sido utilizados para a produção do minimilho. O cultivo desse tipo de milho é pouco expressivo no Brasil, sendo a produção e o processamento agroindustrial pouco tecnificados, se comparados com outros países, além de existir uma escassez de informações em relação ao manejo da cultura, bem como sobre o desempenho dos cultivares. Avaliou-se o desempenho de cultivares de milho em diferentes épocas de semeadura, associado ao efeito do despendoamento das plantas na produção de minimilho. Os experimentos foram instalados em área experimental da Embrapa Milho e Sorgo, em Sete Lagoas, MG, sendo um experimento no ano de 1999 (semeadura em 23/12), dois no ano de 2000 (semeaduras em 20/01 e 12/10) e um em 2001 (semeadura em 02/02). Para cada experimento, o delineamento experimental empregado foi em blocos casualizados, em esquema fatorial 8 (cultivares) x 2 (com e sem despendoamento), com três repetições. Realizaram-se três colheitas, em intervalos de três dias, sendo a primeira três dias após a emissão dos estilos-estigmas. Foram avaliados o peso de espigas empalhadas, o peso de espigas comerciais e o rendimento de espigas comerciais. Entre as cultivares avaliadas, a DKB 929 se destaca, apresentando o melhor desempenho para peso de espigas empalhadas e peso de espigas comerciais, independente da época de semeadura. O despendoamento proporciona aumento na produtividade de espigas comerciais, independente da época de semeadura. Há necessidade de avaliação das cultivares em diferentes épocas, antes da sua recomendação para a produção de minimilho. Para a produção de espigas empalhadas, o aumento na produção devido ao despendoamento depende da época de semeadura.
\end{abstract}

Palavras-chave: Zea mays, minimilho, ambientes, fenologia.

\section{EFFECTS OF CULTIVARS, PLANTS DETASSELINGAND SOWING PERIODS ON BABY CORN PRODUCTION}

\begin{abstract}
Baby corn is the name given to young ears which haven't been fertilized yet and with the advent of canned food industry it started being greatly consumed. Therefore, there was an increase in the cultivated area for this sort of consumption, just like it had happened to
\end{abstract}


green maize some decades before. Different types of maize cultivars - sweet corn, popcorn and regular maize - have been used to produce baby corn although its cultivation is not really expressive and lacks agro-industrial technology and techniques, compared to other countries. Furthermore, little is known about its process of production and performance. The purpose of this research was to evaluate the effects of maize cultivars in different sowing periods and plant detasseling performance on baby corn production. Experiments were carried out at the Brazilian Maize and Sorghum Research Center (EMBRAPA), Sete Lagoas, MG, Brazil, from 1999 till 2001. Trials were planted on December 23, 1999, January 20, 2000, October 12, 2000 and February 02,2001 . The experimental design was a randomized block with $8 \times 2$ factorial scheme ( 8 maize cultivars, with and without detasseling), with three replications. Three baby corn harvests were performed every three days being the first 3 days after style-stigma emission (65 days after sowing). Agronomic characteristics such as the husked ears weight, the baby corn weight and the baby corn yield were evaluated. The DKB 929 cultivar showed better performance for husked ear weight and baby corn weight. Plant detasseling promoted an increase in commercial baby corn weight, regardless the sowing period. The significant interaction cultivar $\mathrm{x}$ sowing period indicates the need to evaluate cultivars in different sowing periods.

Key words: Zea mays, baby corn, environmental conditions, phenology.

O minimilho, também conhecido como "baby corn", é o nome dado à espiga de milho jovem, em desenvolvimento, não fertilizada, ou ao sabugo jovem da espiga de uma planta de milho (Galinat \& Lin, 1988). As plantas para produção de minimilho são semelhantes às de milho normal, e não são, como poderia ser assumido, plantas anãs (Miles \& Zens, 1998).

Com o advento da indústria de conservas, o minimilho passou a ser consumido também na forma de conserva. Assim, houve um crescimento na área cultivada com milho para consumo nessa forma, à semelhança do acontecido com o milho verde.

O colmo, as folhas, as palhas e os estilosestigmas das plantas para produção de minimilho podem ser utilizados para a alimentação animal, por serem ricos em nutrientes, especialmente proteínas, que podem variar de 6 a 14\%. Isso permite que os produtores de minimilho possam ter uma renda adicional na comercialização desses produtos (Lekagul et al., 1981).

Dentre os países produtores de minimilho, a Tailândia é um dos principais, sendo o maior exportador. De 1988 a 2001, a área de cultivo de minimilho na Tailândia aumentou de nove para vinte mil hectares (Kitiprawat, 1989; Chutkaew \& Paroda, 1994; Aekatasanawan, 2001).

No Brasil, a maioria do minimilho consumido é importado na forma de conserva ou enlatado. Essas conservas são reembaladas em recipientes menores, com rótulos da empresa importadora (Santos, 2002). Entretanto, a produção de minimilho no Brasil tem crescido significativamente. Os consumidores nacionais têm dado preferência ao produto nacional, por não apresentarem conservantes e outros aditivos químicos, os quais estão presentes no produto importado (Miles \& Zenz, 1998).

No Brasil, ainda não existem cultivares comerciais específicas para a produção de minimilho, mas já existem alguns programas de melhoramento de milho visando ao desenvolvimento de cultivares específicas para essa finalidade (Pereira Filho et al., 1998a). Várias cultivares de milho têm sido avaliadas, com o intuito de identificar aquelas mais adaptadas às condições tropicais. Têm-se utilizado cultivares selecionadas de germoplasma de milho doce e de pipoca e cultivares prolíficas selecionadas de milho normal, as quais possuem um grande potencial 
para serem utilizadas na produção de minimilho (Galinat \& Lin, 1988; Pereira Filho et al., 1998b).

Pereira Filho et al. (1998a), avaliando cultivares de milho pipoca (CMS 43) e doce (BR 400), constataram que ambas proporcionaram diâmetro e comprimento de espigas dentro dos padrões exigidos pelas indústrias de conservas alimentícias. Algumas características do milho doce foram mais influenciadas pela densidade de plantio do que o milho pipoca, e mesmo assim a cultivar de milho doce manteve os padrões exigidos pela indústria.

Quanto às práticas agrícolas que podem influenciar a produtividade e a qualidade do minimilho, Pereira Filho et al. (1998a) consideraram como principais a densidade de semeadura e a adubação. Ao avaliarem densidades de semeadura entre $87.500 \mathrm{e}$ 237.500 plantas ha $^{-1}$, verificaram que diferentes densidades de semeadura afetaram significativamente $o$ número, o índice e o peso de espigas comerciais e que as densidades de 187.500 e 237.500 plantas $\mathrm{ha}^{-1}$ proporcionaram melhores rendimentos de minimilho.

Desse modo, o sistema de cultivo do minimilho é diferenciado de milho para grãos, principalmente no que se refere à densidade de semeadura, que pode ser até três vezes maior (Pereira Filho et al., 1998b).

Estudos realizados por Sahoo \& Panda (1997), com a cultura do minimilho cultivada sob diferentes doses de nitrogênio e em várias densidades de plantas, durante a época das chuvas e de inverno, na Tailândia, constataram que a produção de minimilho cresceu progressivamente com o aumento da aplicação de $\mathrm{N}$ até $120 \mathrm{~kg} \mathrm{ha}^{-1}$. Durante a época das chuvas, não houve aumento na produção com a aplicação de $\mathrm{N}$ acima de $120 \mathrm{~kg} \mathrm{ha}^{-1}$. No inverno, a dose de $160 \mathrm{~kg} \mathrm{ha}^{-1}$ de $\mathrm{N}$ proporcionou a maior produção de minimilho $\left(1,77\right.$ tha $\left.^{-1}\right)$. Em ambas as épocas, a densidade de plantas de 125.000 plantas ha-1 (40 cm entre linhas x $20 \mathrm{~cm}$ entre plantas) foi a mais vantajosa para a produção e qualidade das espigas de minimilho.

Uma das práticas agrícolas que visam aumentar a produtividade de espigas é a realização do despendoamento, ou seja, o pendão ou a inflorescência masculina pode ser removido para estimular o desenvolvimento mais rápido de espigas. Isso ocorre devido à quebra da dominância apical, onde se localiza a inflorescência masculina, que é um grande consumidor de energia. Com a retirada do pendão, há um estímulo de brotações de gemas laterais, dando origem a novas inflorescências femininas, que poderão ser colhidas como minimilho, três a quatro dias após o despendoamento (Aekatasanawan, 2001).

O despendoamento evita a fertilização, uma vez que, com a polinização e o início da formação do grão, as espigas tornam-se inadequadas sob o ponto de vista comercial. Todavia, o despendoamento resulta em um aumento do custo de produção e, talvez, a uma perda de produção, devido à eliminação de algumas folhas (Aekatasanawan, 2001).

Aekatasanawan et al. (1994) avaliaram oito variedades, com e sem despendoamento, incluindo variedades macho-estéreis. Foi observado maior peso de espigas empalhadas, despalhadas, espigas por planta, relação de espigas empalhadas por espigas despalhadas, nas variedades macho-estéreis, quando comparadas à testemunha Suwan 2, que foi despendoada. Sem a realização do despendoamento, as variedades estéreis produziram, em média, 7,42 tha ${ }^{-1}$ de espigas empalhadas, 1,47 tha $^{-1}$ de espigas despalhadas e 0,93 tha-1 de espigas comerciais. Já as variedades férteis produziram, em média, 4,23 $\mathrm{t}$ ha $^{-1}$ de espigas empalhadas, $0,82 \mathrm{tha}^{-1}$ de espigas despalhadas e 0,56 tha $^{-1}$ de espigas comerciais. Para outros caracteres avaliados, a realização ou não do despendoamento nas variedades macho-estéreis não foi significativa. 
O ponto ideal de colheita do minimilho é quando as espigas estiverem com dois a três dias após a exposição dos estilos-estigmas. Geralmente são efetuadas de duas a três colheitas por planta, dependendo da cultivar e da época de semeadura (Galinat, 1985; Thakur \& Sharma, 1999).

Após a colheita do minimilho, é realizado o despalhamento e a seleção criteriosa de espigas que se enquadram nos padrões comerciais, ou seja, que apresentam tamanhos variando de 4 a $12 \mathrm{~cm}$, diâmetros de 1,0 a $1,5 \mathrm{~cm}$, forma cilíndrica e coloração variando de branco pérola a amarelo claro (Kitiprawat, 1989).

Durante o armazenamento das espigas, a redução no peso devido às perdas de água na evaporação e respiração chega, aproximadamente, a $6,8 \%$ por três dias de armazenagem, reduzindo também a qualidade, devido à maturação do sabugo (Lekagul et al., 1981).

No Brasil, as propriedades agrícolas que produzem minimilho estão próximas das instalações de processamento, com o intuito de evitar problemas com a fermentação, perda do material e reduzir o custo com o transporte. Normalmente, as espigas já embaladas em bandejas protegidas com filme de PVC são transportadas ao consumidor em caminhões refrigerados (Santos, 2002). Outra possibilidade é a comercialização na forma de conservas, geralmente enlatadas ou em vidros específicos para essa finalidade. Vale ressaltar que a maioria da comercialização do minimilho no Brasil é feita dessa forma.

A carência de informações como a falta de pesquisas sobre práticas culturais para a produção de minimilho, identificação de cultivares apropriadas, épocas e densidade de semeadura, práticas especiais como o despendoamento, efeito da adubação e métodos de colheita motivaram a realização deste trabalho, cujo objetivo foi avaliar o desempenho de diferentes tipos de cultivares de milho em diferentes épocas de plantio, associado ao efeito da realização ou não do despendoamento das plantas na produção de minimilho.

\section{Material e Métodos}

Os experimentos foram instalados em área experimental da Embrapa Milho e Sorgo, em Sete Lagoas-MG, em solo classificado como latossolo vermelho de textura argilosa. Foram conduzidos quatro experimentos, sendo um no ano de 1999 (semeadura em 23/12), dois em 2000 (semeaduras em 20/01 e 12/10) e um em 2001 (semeadura em 02/02).

Por ocasião da semeadura, foram aplicados $350 \mathrm{~kg}$ da fórmula 4: 30: 16, com 0,5\% Zn. Foi realizada uma única adubação de cobertura, no estádio de seis folhas, com $100 \mathrm{~kg}$ de N, utilizando-se uréia.

Em todos os experimentos, foi avaliado o comportamento de oito cultivares de milho, incluindo três cultivares de milho comum, híbrido simples DKB 929, híbridos triplos Dina 170 e CO 9621 e cinco cultivares de milhos especiais: DO 04 (doce), FO 01 (silagem), Elisa (doce), Zélia (pipoca) e variedade Pipoca-estéril (minimilho). Foi também avaliada a realização ou não do despendoamento das plantas, que ocorreu no final do estádio fenológico 3 (Fancelli \& Dourado Neto, 1997).

Para cada experimento, o delineamento experimental utilizado foi em blocos casualizados, em esquema fatorial 8 (cultivares) $\times 2$ (despendoamento), com três repetições. A parcela experimental foi composta de quatro linhas de cinco metros de comprimento, sendo considerados como área útil os três metros centrais das duas fileiras centrais. $\mathrm{O}$ espaçamento entre linhas foi de $0,80 \mathrm{~m}$ e a densidade de plantas de 180.000 plantas ha $^{-1}$.

A primeira colheita foi realizada três dias após a emissão dos estilos-estigmas. Foram efetuadas três colheitas por parcela, em intervalos de três dias. $\mathrm{O}$ término da colheita deu-se após a colheita da terceira ou quarta espiga da planta. 
Todas as espigas da parcela foram pesadas com palha (peso de espigas empalhadas). Posteriormente, as espigas foram despalhadas e, em seguida, selecionadas as que se enquadravam no padrão comercial, apresentando diâmetro variando de 0,8 a $1,8 \mathrm{~cm}$, tamanho de 4 a $12 \mathrm{~cm}$, cor variando de branco pérola a amarelo claro, formato cilíndrico, fileira de ovários retilínea, espigas não quebradas e não fertilizadas. Obteve-se, então, o peso de espigas comerciais.

Os dados de peso de espigas empalhadas e comerciais foram expressos em tha- ${ }^{-1}$. O rendimento de espigas comerciais foi obtido pela razão entre o peso de espigas comerciais e o peso de espigas empalhadas.

Todos os dados obtidos em cada experimento foram submetidos inicialmente à análise de variância individual e, posteriormente, foi realizada uma análise de variância conjunta, envolvendo simultaneamente todos os experimentos conduzidos.

As análises de variância e os testes de agrupamento de médias (Scott - Knott, 5\% de probabilidade) foram realizados utilizando o pacote estatístico SAS (SAS Institute, 1995).

\section{Resultados e Discussão}

Pelas análises de variância individuais realizadas, constataram-se diferenças significativas $(\mathrm{P}<0,01)$ para todas as características avaliadas, para a maioria das fontes de variação. Para a interação cultivares e despendoamento, foi constatado efeito significativo $(\mathrm{P}<0,01)$ para o peso de espigas comerciais no experimento de dezembro/1999, rendimento de espigas comerciais no experimento de janeiro/2000 e peso de espigas empalhadas no experimento de outubro/2000. Para o experimento de fevereiro/2001, a interação não foi significativa para nenhuma das características avaliadas. A precisão experimental avaliada pelo coeficiente de variação (CV) variou entre os caracteres, com valores sempre inferiores a $22 \%$.
Pela análise de variância conjunta, constatou-se efeito significativo $(\mathrm{P}<0,01)$ para todas as características avaliadas, para as fontes de variação, épocas de semeadura, cultivares e interação épocas de semeadura e cultivares. Para a fonte de variação despendoamento, ocorreu diferença significativa $(\mathrm{P}<0,01)$ para as características peso de espigas empalhadas e peso de espigas comerciais. No caso da interação cultivares e despendoamento, houve significância $(\mathrm{P}<0,01)$ apenas para o peso de espigas comerciais. A interação épocas de semeadura e despendoamento não foi significativa apenas para o rendimento de espigas comerciais. O coeficiente de variação $(\mathrm{CV})$ variou entre os caracteres, com valores sempre inferiores a $17 \%$.

O peso médio de espigas empalhadas foi de 8,42 $\mathrm{t} \mathrm{ha}^{-1}$, com variação de 10,30 (DKB 929) a 6,30 t ha $^{-1}$ (Dina 170) (Tabela 1). Resultados encontrados por Aekatasanawan (1991) e Domyos \& Oates, com variações de 6,91 a 7,42 $\mathrm{t} \mathrm{ha}^{-1}$, foram menores do que os encontrados em Sete Lagoas.

O peso de espigas empalhadas no experimento instalado em dezembro de 1999 variou de 8,36 (Dina 170) a 13,17 t ha ${ }^{-1}$ (DKB 929), com

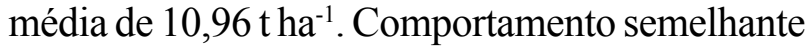
foi observado no experimento de 2001, para as cultivares DKB $929\left(8,84\right.$ t ha $\left.^{-1}\right)$ e Dina $170\left(5,10\right.$ t ha $\left.^{-1}\right)$, sendo, respectivamente, as de melhor e pior desempenho. No experimento de janeiro/2000, a variação foi de 3,86 (Pipoca-estéril) a 8,50 tha h $^{-1}$ (DKB 929), com média de 5,76 t ha ${ }^{-1}$. Já em outubro/2000, a média das cultivares foi de $9,88 \mathrm{t} \mathrm{ha}^{-1}$, com variação de 6,68 (Dina 170) a 11,19 t ha-1 (Zélia). A cultivar DKB 929 destacou-se em relação às outras no plantio de janeiro de 2000. Na média das épocas de plantio, essa cultivar apresentou maior peso de espigas empalhadas, embora não tenha diferido significamante o peso do milho pipoca Zélia e do híbrido triplo CO 9621.

Todas as cultivares tiveram produções superiores em dezembro/1999, com exceção do FO 01 
TABELA 1. Valores médios do peso de espigas empalhadas $\left(\mathrm{t} \mathrm{ha}^{-1}\right)$ de oito cultivares de milho avaliadas em quatro épocas de semeadura. Embrapa Milho e Sorgo, Sete Lagoas, MG, 2002.

\begin{tabular}{lrrrrr}
\hline \multirow{2}{*}{ Cultivares } & \multicolumn{5}{c}{ Épocas de semeadura } \\
\cline { 2 - 6 } & Dez. /1999 & Jan./2000 & Out. /2000 & Fev. /2001 & Médias \\
\hline DKB 929 & $13,17 \mathrm{a}$ & $8,50 \mathrm{a}$ & $10,68 \mathrm{a}$ & $8,84 \mathrm{a}$ & $10,30 \mathrm{a}$ \\
Zélia & $11,88 \mathrm{a}$ & $6,82 \mathrm{~b}$ & $11,19 \mathrm{a}$ & $8,03 \mathrm{a}$ & $9,48 \mathrm{a}$ \\
CO 9621 & $12,64 \mathrm{a}$ & $5,12 \mathrm{c}$ & $10,85 \mathrm{a}$ & $7,80 \mathrm{a}$ & $9,10 \mathrm{a}$ \\
Elisa & $12,19 \mathrm{a}$ & $5,69 \mathrm{c}$ & $10,96 \mathrm{a}$ & $6,03 \mathrm{~b}$ & $8,72 \mathrm{~b}$ \\
DO 04 & $11,16 \mathrm{a}$ & $4,56 \mathrm{c}$ & $9,69 \mathrm{~b}$ & $7,02 \mathrm{a}$ & $8,10 \mathrm{~b}$ \\
FO 01 & $8,69 \mathrm{~b}$ & $6,50 \mathrm{~b}$ & $9,29 \mathrm{~b}$ & $6,22 \mathrm{~b}$ & $7,68 \mathrm{~b}$ \\
Pipoca-estéril & $9,59 \mathrm{~b}$ & $3,86 \mathrm{c}$ & $9,72 \mathrm{~b}$ & $7,38 \mathrm{a}$ & $7,64 \mathrm{~b}$ \\
Dina 170 & $8,36 \mathrm{~b}$ & $5,07 \mathrm{c}$ & $6,68 \mathrm{c}$ & $5,10 \mathrm{~b}$ & $6,30 \mathrm{c}$ \\
\hline Médias & $10,96 \mathrm{~A}$ & $5,76 \mathrm{C}$ & $9,88 \mathrm{~A}$ & $7,05 \mathrm{~B}$ & 8,42 \\
\hline
\end{tabular}

Médias seguidas pela mesma letra, na coluna (minúscula) e na linha (maiúscula) pertencem ao mesmo agrupamento, de acordo com o teste de Scott - Knott, a 5\% de probabilidade.

e da Pipoca-estéril, as quais apresentaram maiores pesos no experimento de outubro/2000. Por outro lado, a maioria das cultivares apresentou menores pesos no experimento de janeiro/2000, com exceção da cultivar FO 01, para a qual se obteve menor peso no experimento de 2001.

A variedade macho-estéril Pipoca-estéril, que apresenta $70 \%$ de esterilidade, apresentou melhor desempenho na última época de semeadura (fev./ 2001), com produtividade acima de 7,0 $\mathrm{t} \mathrm{ha}^{-1}$, e seu pior desempenho foi na segunda época de semeadura (jan./2000), mas, em compensação, obteve altas produtividades em dezembro/1999 $\left(9,59\right.$ tha $\left.^{-1}\right)$ e em outubro/2000 $\left(9,72 \mathrm{t} \mathrm{ha}^{-1}\right)$.
Aekatasanawan (1991), avaliando variedades macho-estéreis, com e sem a realização do despendoamento, encontrou valores semelhantes para o peso de espigas empalhadas em relação à Pipo-

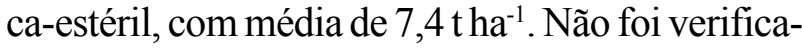
do efeito significativo quando realizado o despendoamento das plantas para essa característica. $\mathrm{O}$ autor afirma que, pelo fato de as variedades serem $100 \%$ estéreis, o despendoamento das plantas pode não ter alterado o peso de espigas empalhadas. Vale ressaltar que as plantas da variedade Pipoca-estéril utilizada neste trabalho apresentam $70 \%$ de esterilidade, o que pode ter contribuído para o aumento 
de peso de espigas empalhadas quando foi realizado o despendoamento (Figura 1).

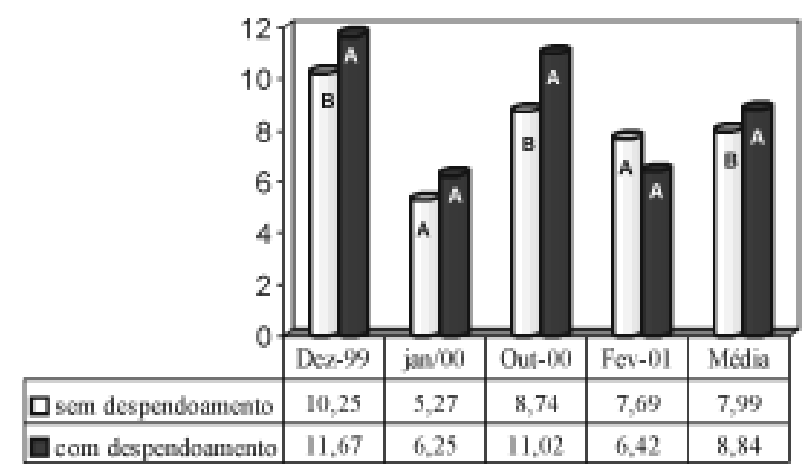

Barras seguidas pela mesma letra não diferem entre si, de acordo com o teste de Scott-Knott, a 5\% de probabilidade.

FIGURA 1. Valores médios do peso de espigas empalhadas $\left(\mathrm{t} \mathrm{ha}^{-1}\right)$, com e sem a realização do despendoamento das plantas, em quatro épocas de semeadura. Embrapa Milho e Sorgo, Sete Lagoas, MG, 2002.

Independentemente da realização do despendoamento das plantas, no experimento de dezembro/1999, obteve-se a maior produção de espigas, com aumento de $14 \%$ na produção quando foi realizado o despendoamento (Figura 1). No experimento de outubro/2000, o aumento foi de $27 \%$ e, para os outros dois experimentos (jan/00 e fev/ 01), a realização do despendoamento não proporcionou aumento significativo na produção.

O peso de espigas comerciais é considerado a característica mais importante para a produção de minimilho. Considerando a média dos quatro experimentos, o peso de espigas comerciais foi de 1,46 tha $^{-1}$, sendo a maior e a menor produtividade para as cultivares DKB $929\left(1,88\right.$ tha $\left.^{-1}\right)$ e FO $01\left(1,15\right.$ tha $\left.^{-1}\right)$ (Tabela 2). Esses resultados são superiores aos relatados por Aekatasanawan (1991), Pereira Filho et al. (1998b) e Miles \& Zens (1998), que obtiveram valores entre 0,42 e 1,09 t ha $^{-1}$ de espigas comerciais, com o espaçamento entre fileiras semelhante ao utilizado neste trabalho.
A cultivar DKB 929 destacou-se como a mais produtiva nos quatro experimentos, com valores sempre superiores a 1,5 tha ${ }^{-1}$. A cultivar Elisa e a DKB 929 foram as mais produtivas no experimento de outubro/2000. No experimento de janeiro/2000, as cultivares Zélia e DKB 929 foram as mais produtivas. As cultivares DO $04\left(1,32 \mathrm{t} \mathrm{ha}^{-1}\right)$, Zélia $\left(1,24 \mathrm{t} \mathrm{ha}^{-1}\right)$, CO $9621\left(1,22 \mathrm{t} \mathrm{ha}^{-1}\right)$, a variedade Pipoca-estéril $\left(1,27\right.$ t ha $\left.^{-1}\right)$ e DKB $929(1,48 \mathrm{t}$ ha $\left.^{-1}\right)$ tiveram os melhores desempenhos no experimento de 2001. De modo geral, o menor peso de espigas comercial foi observado para as cultivares FO 01 e Dina 170.

Nos experimentos instalados em dezembro/ 1999 e outubro/2000, foram observadas maiores produções de espigas comerciais, independentemente da cultivar considerada. A produção média desses experimentos foi de 1,96 e 1,62 tha ${ }^{-1}$, ou seja, em média $58 \%$ superior às produtividades obtidas em janeiro/2000 e fevereiro/2001, nas quais não foram observadas diferenças entre si.

Observou-se que as cultivares de milho doce (Elisa e DO 04) e pipoca (Zélia e Pipoca-estéril) apresentaram desempenho variável nos experimentos conduzidos em 1999, 2000 e 2001. Vale ressaltar que essas cultivares são as mais utilizadas para a produção de minimilho, no Brasil. Os resultados obtidos neste trabalho evidenciam a existência de outras cultivares que também poderão ser utilizadas para a produção de minimilho.

Quanto à rentabilidade do cultivo de minimilho, considerando a comercialização em bandejas (350 g), com preço unitário de R \$ 1,50 (Santos, 2002) e produtividade média obtida nos quatro experimentos, de 1,46 tha ${ }^{-1}$, constata-se que o faturamento nos dois sistemas de cultivos será de $\mathrm{R} \$$ 6,2 mil para o minimilho, bem superior ao obtido com o milho normal. Essa diferença evidencia a possibilidade de agregar valor no cultivo do milho, aumentando a lucratividade, principalmente quando se 
TABELA 2. Valores médios do peso de espigas comerciais $\left(\mathrm{t} \mathrm{ha}^{-1}\right)$ de oito cultivares de milho, avaliadas em quatro épocas de semeadura. Embrapa Milho e Sorgo, Sete Lagoas, MG, 2002.

\begin{tabular}{lccccc}
\hline \multirow{2}{*}{ Cultivares } & \multicolumn{5}{c}{ Épocas de semeadura } \\
\cline { 2 - 6 } DKB 929 & Dez./1999 & Jan./2000 & Out./2000 & Fev./2001 & Médias \\
\cline { 2 - 6 } Elisa & $2,11 \mathrm{~b}$ & $1,18 \mathrm{~b}$ & $2,10 \mathrm{a}$ & $1,02 \mathrm{~b}$ & $1,60 \mathrm{~b}$ \\
CO 9621 & $2,16 \mathrm{~b}$ & $0,84 \mathrm{~b}$ & $1,79 \mathrm{~b}$ & $1,22 \mathrm{a}$ & $1,50 \mathrm{~b}$ \\
Zélia & $1,69 \mathrm{c}$ & $1,44 \mathrm{a}$ & $1,43 \mathrm{c}$ & $1,24 \mathrm{a}$ & $1,45 \mathrm{~b}$ \\
Pipoca-estéril & $1,85 \mathrm{c}$ & $0,87 \mathrm{~b}$ & $1,76 \mathrm{~b}$ & $1,27 \mathrm{a}$ & $1,44 \mathrm{~b}$ \\
DO 04 & $1,79 \mathrm{c}$ & $0,74 \mathrm{~b}$ & $1,59 \mathrm{~b}$ & $1,32 \mathrm{a}$ & $1,36 \mathrm{c}$ \\
Dina 170 & $1,90 \mathrm{c}$ & $0,95 \mathrm{~b}$ & $1,36 \mathrm{c}$ & $0,87 \mathrm{~b}$ & $1,27 \mathrm{c}$ \\
FO 01 & $1,67 \mathrm{c}$ & $0,95 \mathrm{~b}$ & $1,02 \mathrm{~d}$ & $0,95 \mathrm{~b}$ & $1,15 \mathrm{c}$ \\
\hline Médias & $1,96 \mathrm{~A}$ & $1,08 \mathrm{~B}$ & $1,62 \mathrm{~A}$ & $1,17 \mathrm{~B}$ & 1,46 \\
\hline
\end{tabular}

Médias seguidas pela mesma letra, na coluna (minúscula) e na linha (maiúscula), pertencem ao mesmo agrupamento, de acordo com o teste de Scott - Knott, a 5\% de probabilidade.

considera a agricultura familiar, que geralmente dispõe de áreas restritas para o cultivo. Nesse caso, a opção pelo cultivo de minimilho é muito interessante e lucrativa. Vale ressaltar que, caso a comercialização do minimilho seja realizada na forma de conservas, o faturamento por hectare será ainda maior, em torno de R\$ 12 mil.

Considerando a média dos quatro experimentos, o efeito do despendoamento das plantas proporcionou um aumento significativo ( $7 \%$ ) no peso de espigas comerciais (Tabela 3). Verificou-se efeito significativo da interação despendoamento e cultivares. Para as cultivares Elisa, Zélia e FO 01, constatou-se aumento na produção de espigas comerciais quando foi realizado o despendoamento, e a magnitude desse aumento foi de 12\% (Zélia), 19\% (Elisa) e $26 \%$ (FO 01). Para as outras cultivares, não foi constatado aumento na produção de espigas comerciais com o despendoamento. Aetakasanawan et al. (1994) constataram aumentos na produção de espigas comerciais variando de $3,7 \%$ a $32,7 \%$. Essas variações ocorreram devido à interação entre as cultivares e as épocas de semeadura e manejos adotados.

Os resultados obtidos neste trabalho corroboram os obtidos por Grogan (1956), o qual concluiu que o despendoamento possibilita uma maior produção e translocação de fotoassimilados das 
folhas para a espiga, devido à redução no sombreamento das folhas provocado pelo pendão, permitindo maior interceptação de luz, levando a um aumento da produtividade de espigas.

TABELA 3. Valores médios do peso de espigas comerciais $\left(\mathrm{t} \mathrm{ha}^{-1}\right)$ de oito cultivares de milho avaliadas com e sem a realização do despendoamento das plantas. Embrapa Milho e Sorgo, Sete Lagoas, MG, 2002.

\begin{tabular}{lcc}
\hline \multirow{2}{*}{ Cultivares } & \multicolumn{2}{c}{ Peso de espigas comerciais $\left(\mathrm{t} \mathrm{ha}^{-1}\right)$} \\
\cline { 2 - 3 } & Sem despendoamento & Com despendoamento \\
\hline DKB 929 & $1,83 \mathrm{~A}$ & $1,94 \mathrm{~A}$ \\
CO 9621 & $1,56 \mathrm{~A}$ & $1,48 \mathrm{~A}$ \\
Pipoca-estéril & $1,48 \mathrm{~A}$ & $1,40 \mathrm{~A}$ \\
Elisa & $1,46 \mathrm{~B}$ & $1,74 \mathrm{~A}$ \\
Zélia & $1,37 \mathrm{~B}$ & $1,53 \mathrm{~A}$ \\
DO 04 & $1,30 \mathrm{~A}$ & $1,41 \mathrm{~A}$ \\
Dina 170 & $1,23 \mathrm{~A}$ & $1,31 \mathrm{~A}$ \\
Fo 01 & $1,02 \mathrm{~B}$ & $1,28 \mathrm{~A}$ \\
\hline Módias & $1,41 \mathrm{~B}$ & $1,51 \mathrm{~A}$ \\
\hline
\end{tabular}

Médias seguidas pela mesma letra maiúscula na linha não diferem entre si, de acordo com o teste de Scott-Knott, a 5\% de probabilidade.

Para o rendimento de espigas comerciais, foi constatada a presença de interação cultivares e épocas de semeadura. Isso indica que o desempenho relativo das cultivares não foi coincidente nos quatro experimentos conduzidos (Tabela 4).

Em dezembro/1999, a cultivar que apresentou o maior rendimento de espigas comerciais foi a Dina $(22,8 \%)$, e as de menor valor foram a DO 04 $(16,0 \%)$ e a Zélia $(14,17 \%)$. Já no experimento instalado em janeiro/2000, merecem destaque as cultivares Zélia, com $21,1 \%$ de espigas comerciais, Elisa, com 20,6\%, e a Pipoca-estéril, com 22,5\%. Nesse caso, as cultivares CO 9621 (17,0\%), DO 04
$(15,8 \%)$ e FO $01(14,6 \%)$ foram as que apresentaram o menor rendimento de espigas comerciais. $\mathrm{Na}$ semeadura realizada em outubro/2000, mais uma vez foram observados maiores rendimentos de espigas comerciais para as cultivares Dina $170(20,43 \%)$, Elisa (19,63\%), e a Pipoca-estéril (20,37\%). Para este experimento, a cultivar Zélia e FO 01 foram as que apresentaram o menor rendimento de espigas comerciais. O mesmo ocorreu com as cultivares Dina 170, Elisa e a Pipoca-estéril, no experimento de 2001, destacando-se também a cultivar DO 04. Para as demais cultivares, foram observados menores rendimentos de espigas comerciais, os quais não diferenciaram entre si.

Nos experimentos instalados em outubro/ 2000 e fevereiro/2001, obtiveram-se menores rendimentos de espigas comerciais, cujos valores não diferenciaram entre si. Não houve diferenças para essa característica nos experimentos instalados em dezembro/1999 e janeiro/2000.

Considerando a média dos quatro experimentos, as cultivares Dina $170(19,83 \%)$, Elisa (18,72\%), DKB $929(18,38 \%)$ e a variedade Pipoca-estéril $(19,85 \%)$ foram as que apresentaram o maior rendimento de espigas comerciais. Por outro lado, a cultivar FO 01 foi a de pior desempenho para essa característica.

Esses resultados estão de acordo com observações de Pereira Filho \& Furtado (2000), os quais afirmam que o rendimento de espigas comerciais varia em função do cultivar, manejo da cultura e das condições ambientais, existindo evidências da possibilidade de obtenção de até $30 \%$ a mais de espigas comerciais.

Outro fato relevante relacionado ao rendimento de espigas comerciais é sua relação com o peso de espigas comerciais. As cultivares que apresentaram os maiores pesos de espigas comerciais nem sempre foram as que apresentaram os maiores rendimentos de espigas comerciais. Pereira Filho \& 
Carvalho et al.

TABELA 4. Valores médios do rendimento de espigas comerciais de oito cultivares de milho, em percentagem, avaliadas em quatro épocas de semeadura. Embrapa Milho e Sorgo, Sete Lagoas, MG, 2002.

Rendimento de espigas comerciais (\%)

Cultivares

Épocas de semeadura

\begin{tabular}{lccccc} 
& Dez./ 1999 & Jan./2000 & Out./2000 & Fev./2001 & Médias \\
\hline Pipoca-estéril & $19,30 \mathrm{~b}$ & $22,49 \mathrm{a}$ & $20,37 \mathrm{a}$ & $17,24 \mathrm{a}$ & $19,85 \mathrm{a}$ \\
Dina 170 & $22,81 \mathrm{a}$ & $18,78 \mathrm{~b}$ & $20,43 \mathrm{a}$ & $17,29 \mathrm{a}$ & $19,83 \mathrm{a}$ \\
Elisa & $17,41 \mathrm{c}$ & $20,58 \mathrm{a}$ & $19,63 \mathrm{a}$ & $17,24 \mathrm{a}$ & $18,72 \mathrm{a}$ \\
DKB 929 & $19,26 \mathrm{~b}$ & $19,43 \mathrm{~b}$ & $18,02 \mathrm{~b}$ & $16,82 \mathrm{~b}$ & $18,38 \mathrm{a}$ \\
CO 9621 & $17,20 \mathrm{c}$ & $17,03 \mathrm{c}$ & $16,81 \mathrm{~b}$ & $16,35 \mathrm{~b}$ & $16,85 \mathrm{~b}$ \\
DO 04 & $16,01 \mathrm{~d}$ & $15,83 \mathrm{c}$ & $16,31 \mathrm{~b}$ & $19,25 \mathrm{a}$ & $16,85 \mathrm{~b}$ \\
Zélia & $14,17 \mathrm{~d}$ & $21,10 \mathrm{a}$ & $12,83 \mathrm{c}$ & $15,73 \mathrm{~b}$ & $15,96 \mathrm{~b}$ \\
FO 01 & $20,36 \mathrm{~b}$ & $14,62 \mathrm{c}$ & $11,01 \mathrm{c}$ & $15,38 \mathrm{~b}$ & $15,34 \mathrm{~b}$ \\
\hline Médias & $18,31 \mathrm{~A}$ & $18,73 \mathrm{~A}$ & $16,93 \mathrm{~B}$ & $16,91 \mathrm{~B}$ & 17,72 \\
\hline
\end{tabular}

Médias seguidas pela mesma letra, na coluna (minúscula) e na linha (maiúscula), pertencem ao mesmo agrupamento, de acordo com o teste de Scott - Knott, a 5\% de probabilidade.

Furtado (2000) comprovaram, em um trabalho com duas variedades experimentais de milho, que o peso de espigas comerciais foi inversamente proporcional ao rendimento de espigas comerciais, ou seja, 1,5 $\mathrm{t} \mathrm{ha}^{-1}$ (CMS 422), com 28\% de espigas comerciais, e 1,9 tha ${ }^{-1}$ (AGM 2014S3), com $25 \%$ de espigas comerciais.

\section{Conclusões}

É técnica e economicamente viável a produção de minimilho em Sete Lagoas-MG, devido às boas produtividades alcançadas e ao clima favorável para o cultivo de milho, nas diferentes épocas de semeadura.
Existe variabilidade para o peso de espigas empalhadas, peso de espigas comerciais e rendimento de espigas comerciais, evidenciando a importância da escolha adequada das cultivares para a produção de minimilho.

Há necessidade de avaliação das cultivares em diferentes épocas, antes da sua recomendação para a produção de minimilho.

Merece destaque a cultivar DKB 929, que esteve sempre entre as de melhor desempenho, independentemente da época de semeadura.

Para a produção de espigas empalhadas, o aumento na produção devido à realização do despendoamento depende da época de semeadura. 
A realização do despendoamento proporciona aumento no peso de espigas comerciais, independentemente da época de semeadura.

\section{Literatura Citada}

AEKATASANAWAN, C. Hybrid maize technology for rural development in Thailand, in Towards the Year 2000: technology for rural development. Bangkok: Chulalongkorn University, 1991. v. 64. Proceeding of the Internation Conference.

AEKATASANAWAN, C.; CHOWCHONG, S.; JAMPATONG, S.; BALLA, C. Utilization of male sterility for baby corn improvement. Kasetsart Journal, Kasetsart, v. 28, p. 167-170, 1994.

AEKATASANAWAN, C. Baby corn. In: HALLAUER, A.R. (Ed.). Specialty Corns. 2. ed. Boca Raton: CRC Press, 2001. v. 2, cap. 9, p. 275293.

BRANDALIZZE, V. Milho do contexto mundial. In: CONGRESSO NACIONAL DE MILHO E SORGO, 23., 2000, Uberlândia. Palestras... Sete Lagoas: ABMS/Embrapa Milho e Sorgo/Universidade Federal de Uberlândia, 2000. CD-ROM.

CHUTKAEW, C.; JAMPATONG, S.; AETAKASANAWAN, C. Research and development of corn variety, Suwan 3. In: UNIVERSITY OF KASETSART ANNUAL CONFERENCE, 27, 1989, Bangkok. Proceedings... Bangkok, 1989. p.191-197.

CHUTKAEW, C.; PARODA, R. S. Baby corn production in Thailand: a success story. Bangkok: APAARI/FAO/Regional Office for Asia and the Pacific, 1994. 20 p.

DOMYOS, S.; OATES, C.G. Efficiency of some selected organic wastes in revenue of baby corn. In: UNIVERSITY OF KASETSART ANNUAL
CONFERENCE, 37., 1999, Bangkok. Proceedings... Bangkok, 1999. p.92-97.

FANCELLI, A. L.; DOURADO-NETO, D. Fenologia do milho. In: FANCELLI, A. L.; DOURADO-NETO, D. (Coord.). Tecnologia da produção de milho. Piracicaba: ESALQ/USP, 1997. p. 131-140.

GALINAT, W. C. Silkless baby corn, seed production genetics. Maize Genetics Cooperative, Wallingford, n. 59, p. 102-112, 1985.

GALINAT, W. C.; LIN, B. Y. Baby corn: Production in Taiwan and future outlook for production in the United States. Economic Botany, New York, v. 42, n. 1, p. 132-134, Jan./Mar. 1988.

GROGAN, C. O. Detasseling responses in corn. Agronomy Journal, Madison, v. 48, n. 6, p. 247248, June 1956.

KITIPRAWAT, S. Other aspects of the economy. Bangkok Bank Monthly Review, Bangkok, p. 450-453, Nov. 1989.

LEKAGUL, T.; PERNMAMKHONG, S.; CHUTKAEW, C.; BENJASIL,V. Field corn variety for young ear corn production. National Corn and Sorghum Program Annual Report, Bangkok, v. 13, p. 201-205, 1981.

MILES, C.; ZENS, L. The web of Science. Washington: Washington State University, 1998. Disponível em: <http://agsyst.wsu.edu; milesc@wsu.edu>. Acesso em: 27 out. 2001.

PEREIRA FILHO, I. A.; FURTADO, A. A. L. Minimilho: mais uma opção para o produtor brasileiro e para a indústria de conservas alimentícias. In: CONGRESSO NACIONAL DE MILHO E SORGO, 23., 2000, Uberlândia. Palestras... Sete Lagoas: ABMS/Embrapa Milho e Sorgo/Universidade Federal de Uberlândia, 2000. CD-ROM. 
PEREIRA FILHO, I. A.; GAMA, E. E. G.; CRUZ, J. C. Minimilho: efeito de densidade de plantio e cultivares na produção e em algumas características da planta de milho. Sete Lagoas: EMBRAPACNPMS, 1998a. 6 p. (EMBRAPA - CNPMS. Pesquisa em Andamento, 23).

PEREIRA FILHO, I. A.; GAMA, E. E. G.; FURTADO, A. A. L. A Produção do Minimilho. Sete Lagoas: EMBRAPA-CNPMS, 1988b. 4 p. (EMBRAPA-CNPMS. Comunicado Técnico, 7).

SAHOO, S. C.; PANDA, M. M. Fertilizer requirement of baby corn (Zea mays $\mathrm{L}$ ) in wet and winter seasons. Indian Journal of Agricultural
Sciences, New Delhi, v. 67, n. 9, p. 397-398, Sept. 1997.

SANTOS, M. R. Biblioteca virtual [mensagem pessoal]. Mensagem recebida por <saporibr@terra.com.br>em 8 jan. 2002.

SAS INSTITUTE. SAS users guide: statistics. 5. ed. Cary, NC, 1995. 1290 p.

THAKUR, D. R.; SHARMA, V. Effect of varieties rates of nitrogen and its schedule of aplication in baby corn (Zea mays L.). Indian Journal of Agricultural Sciences, New Delhi, v. 62, n. 2, p. 93-95, Feb. 1999. 